\title{
ISC 2018 Preface
}

2018 2nd AASRI International Conference on Intelligent Systems and Control (ISC 2018) will be held in Lima, Peru, December 27-29, 2018. ISC 2018 is sponsored by American Applied Sciences Research Institute, USA. ISC 2018 is also technically co-sponsored by University of Wisconsin, USA, University of Gothenburg, Sweden and Aalto University, Finland.

A major goal and feature of ISC 2018 is to bring academic scientists, engineers, industry researchers together to exchange and share their experiences and research results about most aspects of Intelligent Systems and Control etc., and discuss the practical challenges encountered and the solutions adopted.

ISC 2018 received 139 submissions. All full submissions were peer reviewed and evaluated based on originality, technical and research content depth, correctness, relevance to conference, contributions, and readability. Submissions were chosen based on technical merit, interest, applicability, and how well they fitted a coherent and balanced technical program. Finally, only 45 best papers were selected as regular papers with the acceptance rate at about $32.4 \%$. iThenticate software was also used for plagiarism detection to ensure the originality of ISC 2018 proceedings.

All accepted papers of ISC 2018 will be published by MATEC Web of Conferences Proceedings (ISSN: 2261-236X). ISC 2018 covered the topics as follows:

1. Control and Automation;

2. Computer Science and Information Engineering;

3. Biological and Chemical Engineering;

4. Management Science and Engineering.

We would like to express our deep appreciation and gratitude to all the people who review the submissions. Then we would also show our sincere thanks to all staff without whose help we can't carry out the important steps during the process of conference preparation. In addition, thanks for your support and participation.

Sincerely

ISC 2018 International Organizing Committee 